\title{
Malignant melanomas contain only the vimentin type of intermediate filaments
}

Jörg Caselitz, Michael Jänner, Eckhardt Breitbart, Klaus Weber, and Mary Osborn

Virchows Arch [Pathol Anat] (1983) 400:43-51

The legend of Figure 3 on page 48 should read as follows:

Fig. 3a-e. Frozen sections from case $1(\mathbf{a}-\mathbf{c}, \mathbf{e}-\mathbf{f})$, stained with antibodies to vimentin (a), keratin (b), desmin (c), GFAP (e) and neurofilaments (f). Note that the tumour cells are positive with antibodies to vimentin and negative with antibodies to other intermediate filament types. $\mathbf{d}$ Shows a frozen section of an additional case of an anaplastic carcinoma stained with antibodies against keratin by the immunoperoxidase technique. Magnification: a $\times 410$, b-f $\times 250$ 